In press (2006). In: E. Trauth (Ed.), Encyclopedia of Gender and Information Technology. Hershey, PA: Information Science Publishing.

\title{
Gender and the Culture of Computing in Applied IT Education
}

\author{
Susan C. Herring \\ Christine Ogan \\ Manju Ahuja \\ Jean C. Robinson \\ Indiana University, Bloomington
}

\section{Introduction}

The "shrinking pipeline" of women who ascend through the ranks in computer science education programs and careers is by now a familiar problem. Women drop out at rates faster than men at all levels of educational and professional advancement, resulting in a gender gap that is especially pronounced at the highest levels of the computing workforce, and that has not narrowed appreciably at any level in over 20 years (Camp, 1997; ITAA, 2005; Vegso, 2005). Efforts to move more women into the pipeline at lower levels have met with limited success (cf. the Carnegie Mellon experience as reported by Margolis \& Fisher, 2002); girls and women still express less interest than boys and men in studying computer science and in pursuing information technology (IT) careers (Bentson, 2000; Vegso, 2005).

A reason often cited in the literature is the masculine culture of many computer science programs and IT workplaces, which is perceived by many women as alien and unwelcoming (Bentson, 2000; Spertus, 1991; Turkle, 1988). Even when institutions make efforts to treat women and men equally or accord women special consideration in admissions and hiring decisions, attitudes discouraging women from entering computing persist, both within the institutions and in society at large. Sometimes these attitudes are expressed overtly: underground "hacker" culture is notoriously antagonistic to women (Gilboa, 1996), and even mainstream computer aficionados respond with resistance and sexist jokes to proposals to recruit more girls and women to study computer science (Slashdot.org, 2005). Moreover, there is a widespread perception that computer experts are socially-isolated "geeks" or "nerds" obsessed with technology, a mode of being that women, who tend to be more socially oriented, find unappealing (Margolis \& Fisher, 2002; Turkle, 1988).

Fortunately, the situation for computer science does not tell the whole story. In the latter part of the $20^{\text {th }}$ century, the expansion of computing and the Internet fueled the rise of applied information technology (IT) fields in which technical skills, rather than being developed for their own sake, are increasingly put to use in the service of human needs. Applied fields such as information science, information systems, and instructional technology have gained strength, and a new interdisciplinary field, informatics, has emerged. At the same time, interest in computer science itself is declining, especially among women (ITAA, 2005; Vegso, 2005). In this chapter we explore the possibility that 
applied IT fields may provide more women-friendly cultures, while still focused on technology. The larger question underlying this exploration is: Does applied IT education have the potential to bridge the "gender computing gap?"

\section{Background}

Previous research has focused mostly on problems faced by women in computer science, especially in undergraduate-level education (Camp, 1997; Cohoon, 2001; Spertus, 1991). Many influences have been cited as contributing to the educational gender gap in computer science, including aspects of institutional culture such as lack of role models (Pearl et al., 1990), mentoring and advising (Whiteley et al., 1991), informal networking (Smith-Lovin \& McPherson, 1993) and a sense of belonging and identity (Ely, 1995); work-family conflict (Netemeyer et al., 1996); and teaching styles (Cohoon, 2001; Turkle, 1988).

One of the most often-cited factors that discourage girls and women from studying computer science is the culture of computing itself: computing is historically and conventionally associated with masculinity, an association that attracts boys to computers who then become role models for other boys, creating environments in which girls feel marginalized (Hacker, 1990; Turkle, 1988). Margolis and Fisher (2002) argue that "women are further alienated by a stifling "geek culture" that celebrates obsessive computing at the expense of broad interests." Hackers are perceived as keeping exceptionally long hours and late nights, and manifesting "highly focused, almost obsessive behavior" (Frenkel, 1990). For many women, this work ethic conflicts with their desire to start a family, or, if they are older, their actual family responsibilities. Meanwhile, hackers, who are predominantly male, are seen as being "bright and creative," while women remain on the periphery. Rasmussen and Hapnes (1991) suggest that this type of culture is important in producing and reproducing male domination in higher education in computer-related fields, and that it influences the integration of women and their position within the field of computing.

The abstractness of much computer science instruction exacerbates the gender-biased culture, in that girls are more likely to be interested in real-world problem solving in contexts involving human users than in machines and programming languages (Clarke, 1992; Ray, Sormunen, \& Harris, 1999). A related deterrent for women is that most introductory computer science courses focus on programming skills rather than concepts of computer science. Girls and women like IT, the findings suggest, but want to do something with it to improve the world; they are not satisfied with mastering computing skills for their own sake.

Applied fields such as information science, information systems, and instructional systems technology have an a priori advantage over computer science when it comes to attracting future female professionals. They are grounded in the disciplines of real-world problems, e.g., business, education, and information management. Indeed, while women are significantly underrepresented in the IT workforce overall (ITAA, 2005; National Council for Research on Women, 2001), especially in computer science (Bryant \& Vardi, 2002), applied careers such as education and library and information science attract 
higher proportions of women (e.g., Maata, 2003). However, research on the status of women in these professions shows mixed outcomes. On the one hand, women in applied disciplines are more likely to achieve professional parity or near parity with men (Quint, 1999; Wolverton, 1999). On the other hand, even in female-predominant applied professions such as education and library science, most high-ranking administrators are men (Growe \& Montgomery, 2000; McDermott, 1998). Moreover, men tend to be disproportionately represented in IT work in these fields, which also tends to be more highly paid and more prestigious (see, e.g., Harris, 2000 for library and information science).

Little has yet been written about what leads women (or men) to choose applied IT careers, or what kinds of disciplinary cultures they encounter when they decide to study an applied IT domain. That is, there is no body of literature directly comparable to that available for computer science on which to base predictions about the long-term effects of the growth of applied IT fields on the gender computing gap. To address this research gap, we initiated the Information Technology Workforce (ITWF) project.

\section{Information Technology Workforce project}

The Information Technology Workforce (ITWF) project, funded by the National Science Foundation, ${ }^{1}$ has since September 2003 been collecting and analyzing data on the experiences, attitudes, and outcomes of women and men in IT programs at five large public universities in the United States. ${ }^{2}$ The focus is on students at all levels (undergraduate, master's, and doctoral) majoring in applied IT disciplines, specifically: Information Science/Studies (traditionally associated with Library Science), Information Systems (associated with Management in Business Schools), Instructional Technology (typically found in Schools of Education), and Informatics (a new, interdisciplinary field, with roots in computing applications to medicine). We expected to find differences among these fields and between applied fields and computer science; more generally, we expected that more female-oriented ("women-friendly") disciplinary cultures would produce more successful outcomes (Jones, 1990), where success is defined both in terms of the quantity of women who enter IT-related educational programs, and the quality of their educational experiences (Ahuja, et al., 2004).

Data collection for the project as a whole is via web-based surveys, telephone interviews, and face-to-face interviews with students, faculty and staff in the IT programs. In this chapter, we focus on findings from an initial Web survey of all IT student majors in the five universities (from the four applied IT fields plus computer science) that took place in Spring 2004. The survey asked 100 questions about the students' experience, behaviors, and attitudes regarding computers, their parents' occupations and attitudes toward gender roles, student demographic information, and information about mentoring, stress and burnout in their academic environment (Ogan, et al., in press). ${ }^{3}$ The results of this survey were revealing of the attitudes and experiences that influence students in their selection of an IT career. 


\section{Selected Findings}

We expected to find more women in the applied programs than in computer science, and the responses to our survey supported this expectation. Whereas four times as many males as females responded from Computer Science (CS) programs, in all applied programs combined, the gender ratio was roughly balanced. The discipline with the highest number of female respondents was Library and Information Science (LIS), followed by Instructional Systems Technology (IST). Of the applied fields, Information Systems (IS) had the most male respondents. In the new field of Informatics (I), we also heard from more men than women. These response rates mirror the gender demographics of students enrolled in each program. That is, the more traditionally "feminine" the applied disciplinary context (libraries, education, vs. business, computers), the more women choose to study it still in 2004.

We then considered what kinds of people select IT majors of one type or the other. Three distinct patterns emerged, showing variation according to gender, IT discipline, and the interaction between gender and discipline.

\section{Gender-based variation}

For some survey questions, men and women tended to answer differently, regardless of their program of IT study. ${ }^{4}$ For example, one question asked students to assess the relative importance they place on their career and their personal life. While most people answered that the two are equally important, females were more likely to choose the balanced response, while males were more likely to say that their careers are more important. This is consistent with previous observations that men in IT are more focused on their work, while women seek a more balanced lifestyle (Frenkel, 1990; Margolis \& Fisher, 2002).

Another series of questions asked about work/life balance as a potential cause of stress. Most students answered 'occasionally' or 'seldom' to questions about whether school work interferes with personal life and vice versa. However, women were more likely to say that school strain affects their personal life all the time, and men were more likely to respond that it never does. This could be a reflection of women having greater domestic responsibilities (cf. Netemeyer et al., 1996); more of the female than male survey respondents said they were married and/or had children at home.

Unsurprisingly, most of the IT students reported that they feel very comfortable using computers. However, here, too, a gender pattern is evident. Males in all majors were more likely to answer that they are very comfortable, whereas females gave most of the "somewhat comfortable" or "not at all comfortable" responses; this includes women in CS. Women also reported learning to use computers later than men, and playing fewer computer games when they were children. ${ }^{5}$

These results support previous findings on gender differences in early computer experience and in computer self-efficacy (Durndell \& Haag, 2002; Fromme, 2003), 
suggesting that some manifestations of the gender computing gap persist in applied IT disciplines.

\section{Discipline-based variation}

A number of differences also emerged within the IT disciplines, independent of respondent gender. A common tendency was for responses for LIS and IST to pattern together, in contrast to responses for CS and IS, with Informatics falling in between. For example, when asked to weigh the relative importance of their career vs. their personal life, students in IS and CS were more likely to indicate that career was more important, and students in LIS and IST were more likely to say that their personal lives mattered more. Perhaps not coincidentally, students in IST and LIS also expressed greater satisfaction with their majors than did the IS and CS students.

Conversely, when asked what attracted them to their IT career choice, students in IS singled out earning a good living, and students in CS cited the challenge inherent in the subject matter. These considerations were rated less important by students in IST and LIS, for whom helping others was the highest consideration.

Disciplinary differences were also found with regard to students' backgrounds and childhood experiences. CS and IS students were more likely to have had a father and/or a mother who worked in an IT-related profession. CS, IS, and Informatics students clustered together in terms of where and when they first started using computers (at home, before or during their elementary school years) and the amount they played computer games as children ('very frequently' or 'frequently'). Of those who answered that they didn't learn to use a computer until high school or college, and played games 'rarely' or 'never,' most were from IST and LIS.

When asked what kind of job they expected to find after graduation, a majority of the respondents, with the exception of IST students, answered 'scientific or technical.' In addition, CS students preferentially indicated 'university teaching and research,' and IS students indicated 'administrative/managerial, 'consulting' and 'sales.' IST students responded 'consulting' and 'K-12 teaching,' and LIS students indicated 'administrative/managerial,' 'clerical,' and 'other.' It is hardly surprising that different disciplines target different careers; however, the students' career expectations in CS and IS (e.g., industry researcher, professor) tend to be higher status and better paid than those in IST and LIS (e.g., K-12 teaching, clerical). Computer science and business are traditionally "masculine" fields, whereas education and library science are traditionally considered "feminine" professions.

\section{Gender and discipline variation}

In the third and final pattern of survey results, gender and IT discipline interact. Specifically, males in traditional masculine disciplines tend to pattern together with females in traditional feminine disciplines, and females in traditional masculine disciplines pattern together with males in traditional feminine disciplines. These results 
suggest a natural mapping between the gender of the student and the traditional gender associations of the discipline.

For example, the survey asked students to indicate their degree of satisfaction with their major. While most answered 'very satisfied,' CS men and IST/LIS women were overrepresented on that response. The inverse pattern was found for the less enthusiastic response 'somewhat satisfied:' CS women and IST/LIS men were overrepresented. In particular, women in IST and LIS selected 'very satisfied' much more often than did women in CS, consistent with our expectations that IST and LIS are more "womenfriendly" cultures (Jones, 1990).

Or consider another set of results, in response to the question: How similar are your values to those of your field? IS males and IST/LIS females were most likely to answer 'very similar,' and I females and IST/LIS males were most likely to answer 'not at all similar.' If we consider Informatics to be part of the CS/IS cluster, this instantiates the same pattern.

Students' confidence about finding a job after graduation displays a similar crossdistribution. Males in CS and females in IST/LIS were most likely to answer that it will be 'very easy' to find a job; LIS males and male students in CS and Informatics were most likely to answer 'very hard,' and women in CS and Informatics were overrepresented in the 'don't know' category. There seem to be two types of male CS student; those who are very confident, and those who are more pessimistic about their job prospects. Apart from this, these results also fit the tendency for confidence and satisfaction to accompany a mapping of student gender on to IT discipline.

\section{Discussion}

The results of a web-based survey of students in different IT programs in five US universities reveal gender differences among students, differences among IT disciplines, and a mapping of gender on disciplinary cultures, all of which potentially affect students' choice of and satisfaction with an IT career.

Somewhat discouragingly, women in applied IT programs, like women in computer science, have less early computer experience and less confidence in their computing abilities than their male peers (Ogan, et al., in press). At the same time, female students' preference for a balanced lifestyle may help to explain why more women choose applied IT majors than CS. The most popular majors among women are those that are traditionally feminine, in which there are more women peers and role models, and which value using technology to help people. Fewer women choose IT majors where the focus is on technology for its own sake (in the case of CS) or making money (in the case of IS), although the women who choose those majors appear to do so for those reasons, similar to men. Most intriguingly, both genders report greater satisfaction with and optimism about their career choices in IT disciplines that mirror the gendered cultures found in society at large. 
These findings are simultaneously encouraging and problematic. On the one hand, they suggest that the rise of applied IT fields does indeed open the door to more women studying and working in IT. Specifically, the findings indicate that IT programs located in traditionally "women-friendly" contexts may be more accessible and appealing to women, and by extension, that other IT contexts might evolve to become more womenfriendly as well. Informatics is an example of a discipline whose culture has not yet become fixed; in this study it tended to pattern weakly with CS and IS, but that tendency could shift.

At the same time, the survey findings are problematic in that they reinscribe cultural stereotypes about gender roles and interests in the IT domain. Moreover, a positive interpretation of the results assumes an equivalence between the various IT fields that is more illusory than real. "Feminized" professions such as instructional design and librarianship still have less status and are lower paid, even when they incorporate IT (Lorenzen, 2002). Moreover, the computing technology involved is typically less rigorous than in computer science (e.g., it may not require practitioners to know how to program a computer). Does women's greater satisfaction with applied IT programs help to bridge the gender IT gap, or does it reproduce a larger societal status quo, of women as less technology- and career-oriented?

Ideally, IT study should be equally accessible and rewarding for women interested in hard-core computing, and men interested in human applications, as it is for men interested in, for example, grid structures, or women interested in information management or educational applications. Again, Informatics may help to bridge the gap, if a culture can be forged in which technical rigor is balanced with a focus on computing applications that benefit people.

\section{Conclusion}

This study has raised a previously unasked question about the potential of applied IT fields to close the gender computing gap. The question remains, for the most part, unanswered; further research needs to be done, for example, to compare the IT content of applied IT programs, and to take national culture (in addition to disciplinary culture) into account in assessing the appeal and outcomes of different approaches to IT. In the meantime, enrollments in CS are declining in U.S. universities (Vegso, 2005) and the IT workforce is aging (ITAA, 2005), but society's need for IT expertise remains high. In the future, it is likely that career seekers of both genders will turn increasingly to applied IT and to the new interdisciplinary paradigms emerging from combinations of computing, information studies, and other fields (Berghel \& Sallach, 2004). It is important to understand the social dynamics and implications of these trends, in the hope that we may be able to shape them into gender-equitable configurations. 


\section{References}

Ahuja, M., Herring, S. C., Ogan, C., \& Robinson, J. C. (2004). Exploring antecedents of gender equitable outcomes in IT higher education. Proceedings of the 2004 SIGMIS Conference on Computer Personnel Research: Careers, Culture, and Ethics in a Networked Environment, 120-123.

Bentson, C. (2000). Why women hate I.T. CIO Magazine, September 1. Retrieved June 15, 2005 from http:/www.cio.com/archive/090100/women.html

Berghel, H., \& Sallach, D. L. (2004, June). A paradigm shift in computing and IT education. Communications of the ACM, 47, 83-88.

Bryant, R. E., \& Vardi, M. Y. (2002, March). 2000-2001 Taulbee Survey. Hope for more balance in supply and demand. Computing Research News, March, 4-11. Retrieved June 15, 2005 from http://www.cra.org/CRN/articles/march02/bryant.vardi.html

Camp, T. (1997). The incredible shrinking pipeline. Communications of the ACM, 40 (10), 103-110.

Clarke, S. (1992). Strategies for involving girls in computer science. In: C. Martin \& E. Murchie-Beyma (Eds.), Search for Gender Free Paradigms for Computer Science Education (pp. 71-86). Eugene, OR: International Society for Technology in Education.

Cohoon, J. M. (2001) Toward improving female retention in the computer science major. Communications of the ACM. 44 (5), 109-114.

Durndell, A., \& Haag, Z. (2002). Computer self efficacy, computer anxiety, attitudes towards the internet and reported experience with the Internet, by gender, in an East European sample. Computers in Human Behavior, 18, 521-535.

Ely, R. J. (1995). The power in demography: Women's social construction of gender identity at work. Academy of Management Journal, 38 (3), 589-634.

Frenkel, K. A. (1990). Women and computing. Communications of the ACM, 33 (11), 3346.

Fromme, J. (2003). Computer games as a part of children's culture. Game Studies, 3 (1). Retreived July 21, 2004 from http://www.gamestudies.org/0301/fromme/

Gilboa, N. (1996). Elites, lamers, narcs and whores: Exploring the computer underground. In: L. Cherny \& E. Weise (Eds.), wired_women (pp. 98-113). Seattle: Seal Press.

Growe, R., \& Montgomery, P. (2000). Women and the leadership paradigm: Bridging the gender gap. National FORUM of Educational Administration and Supervision Journal, 17E (4). Retrieved July 21, 2004 from http://www.nationalforum.com/Miscellaneous/Archives_main.htm 
Harris, R. (2000). Squeezing librarians out of the middle: Gender and technology in a threatened profession. In: E. Balka \& R. Smith (Eds.), Women, Work and Computerization: Charting a Course to the Future. Proceedings of the 7th International Conference on Women, Work and Computerization. Vancouver, British Columbia: June 2000 (pp. 250-259). Boston: Kluwer Academic Publishing.

ITAA. (2005, June 21). Untapped Talent: Diversity, Competition, and America's High Tech Future. Arlington, VA: The Information Technology Association of America. Retrieved June 25, 2005 from http://www.itaa.org/eweb/upload/execsummdr05.pdf

Jones, K. B. (1990). Citizenship in a woman-friendly polity. Signs, 15 (4), 781-812.

Lorenzen, M. (2002). Education schools and library schools: A comparison of their perceptions by academia. Retrieved July 21, 2004 from http://www.michaellorenzen.com/libraryschool.html

Maata, S. (2003, October). Salaries stalled, jobs tight. Library Journal, October 15. Retrieved July 21, 2004 from: http://www.libraryjournal.com/article/CA325077

Margolis, J., \& Fisher, A. (2002). Unlocking the Clubhouse: Women in Computing. Cambridge, MA: MIT Press.

McDermott, E. (1998). Barriers to women's career progression in LIS. Library Management, 19 (7), 416-420.

National Council for Research on Women (2001). Balancing the Equation: Where Are Women \& Girls In Science, Engineering \& Technology? New York: NCRW.

Netemeyer, R.G., Boles, J.S., \& McMurrian, R. (1996). Development and validation of work-family conflict and family-work conflict scales. Journal of Applied Psychology 81(4), 400-410.

Ogan, C., Ahuja, M., Robinson, J. C., \& Herring, S. C. (In press). Gender differences among students in computer science and applied information technology. In: W. Aspray \& J. McGrath Cohoon (Eds.), Women and Information Technology: Research on the Reasons for Under-Representation. Cambridge: MIT Press.

Pearl, A., Pollack, M. E., Riskin, E., Thomas, B., Wolf, E., \& Wu, A. (1990). Becoming a computer scientist. Communications of the ACM, 33 (11), 48-57.

Quint, B. (1999, December). Gender equity in salaries achieved for some information professionals, but not for others. Information Today, 16 (11), 60-61.

Rasmussen, B., \& Hapnes, T. (1991). Excluding women from the technologies of the future: A case study of the culture of computer science. Futures, 23 (10), 1107-1119. 
Ray, C. M., Sormunen, C., \& Harris, T. M. (1999). Men's and women's attitudes toward computer technology: A comparison. Office Systems Research Journal, 17 (1), Spring. http://www.nyu.edu/education/alt/beprogram/osrajournal/ray.PDF

Slashdot.org (2005). Young women encouraged to go for IT. Retrieved February 27, 2005 from http://it.slashdot.org/article.pl?sid=05/02/26/193215

Smith-Lovin, L., \& McPherson, J. M. (1993). You are who you know: A network approach to gender. In: P. England (Ed.), Theory on Gender/Feminism on Theory. New York: Aldine De Gruyter.

Spertus, E. (1991). Why are there so few female computer scientists? Available for a fee from http://people.mills.edu/spertus/Gender/why.html

Turkle, S. (1988). Computational reticence: Why women fear the intimate machine. In C. Kramarae (Ed.), Technology and Women's Voices. NY: Routledge \& Kegan Paul.

Vegso, J. (2005, May). Interest in CS as a major drops among incoming freshmen. Computing Research News, 17 (3). Retrieved June 15, 2005 from http://www.cra.org/CRN/articles/may05/vegso

Whitely, W., Dougherty, T. W., \& Dreher, G. F (1991). Relationship of career mentoring and socioeconomic origin to managers' and professionals' early career progress. Academy of Management Journal, 34 (2), 331-351.

Wolverton, M. (1999). The school superintendency: Male bastion or equal opportunity? Advancing Women. Retrieved July 21, 2004 from http://www.advancingwomen.com/awl/spring99/Wolverton/wolver.html

\footnotetext{
Notes

${ }^{1}$ National Science Foundation IT Workforce Grant \#0305859, "Toward Gender Equitable Outcomes in Higher Education: Beyond Computer Science."

${ }^{2}$ Universities were selected that offered computer science plus a minimum of two applied IT programs.

31768 students responded to the survey, of whom 1516 indicated their gender.

${ }^{4} \mathrm{~A}$ 'finding' in the following discussion indicates a result for which a gender or discipline had values well above the mean for the specified discipline, based on descriptive statistics. Statistical significance was not measured and no claims of significant differences are made.

${ }^{5}$ See Ogan et al. (in press) for more detailed discussion of gender differences in the survey responses.
} 